\title{
Mechanistic Study of Wettability Alteration Using Surfactants with Applications in Naturally Fractured Reservoirs
}

\author{
Mehdi Salehi ${ }^{1}$, Stephen J. Johnson ${ }^{2}$, Jenn-Tai Liang ${ }^{1} *$ \\ ${ }^{1}$ Department of Chemical and Petroleum Engineering, University of Kansas, \\ 1530 W.15th St. Lawrence KS 66045-7609 \\ 2 Tertiary Oil Recovery Project, University of Kansas, \\ 1530 W.15th St. Lawrence KS 66045-7609
}

*jtliang@ku.edu

RECEIVED DATE (to be automatically inserted after your manuscript is accepted if required according to the journal that you are submitting your paper to)

Mechanistic Study of Wettability Alteration Using Surfactants

In naturally fractured reservoirs, oil recovery from waterflooding relies on the spontaneous imbibition of water to expel oil from the matrix into the fracture system. The spontaneous imbibition process is most efficient in strongly water-wet rock where the capillary driving force is strong. In oil- or mixedwet fractured carbonate reservoirs, however, the capillary driving force for the spontaneous imbibition process is weak and therefore, the waterflooding oil recoveries are low. The recovery efficiency can be improved by dissolving low concentrations of surfactants in the injected water to alter the wettability of the reservoir rock to a more water-wet state. This wettability alteration accelerates the spontaneous imbibition of water into matrix blocks, thereby increasing the oil recovery during waterflooding. Several mechanisms have been proposed to explain the wettability alteration by surfactants but none have been verified experimentally. Understanding of the mechanisms behind wettability alteration could help to improve the performance of the process and aid in identification of alternative surfactants for use in field applications. Results from this study revealed that ion-pair formation and adsorption of surfactant molecules through interactions with the adsorbed crude oil components on the rock surface are the two main mechanisms responsible for the wettability alteration. Previous researchers observed 
that for a given rock type, the effectiveness of wettability alteration is highly dependent upon the ionic nature of the surfactant involved. Our experimental results demonstrated that ion-pair formation between the charged head groups of surfactant molecules and the adsorbed crude oil components on rock surface was more effective in changing the rock wettability toward a more water-wet state than the adsorption of surfactant molecules as a monolayer on the rock surface through hydrophobic interaction with the adsorbed crude oil components. By comparing two anionic surfactants with different charge densities, we propose that wettability alteration processes might be improved through the use of dimeric surfactants, which have two charged head groups and two hydrophobic tails. Gemini surfactants where the molecules are joined at the head end are likely to be effective when ion-pair formation is the wettability alteration mechanism and bolaform surfactants, in which molecules are joined by the hydrophobic tails, should be more effective in the case of surfactant monolayer adsorption.

Spontaneous Imbibition, Wettability, Surfactant, Mechanisms, Biosurfactant

\section{Introduction}

Most of the world's oil reservoirs are found in carbonate rocks, many of which contain fractures with high hydraulic conductivity surrounding low-permeability matrix blocks that are mixed- to oil-wet. ${ }^{1,2}$ After the primary production period, waterflooding is often performed to increase the recovery efficiency. In fractured reservoirs, oil recovery from waterflooding relies on the spontaneous imbibition of water to expel oil from the matrix into the fracture system. The spontaneous imbibition process is most efficient in strongly water-wet rock where the capillary driving force is strong. In oil- or mixedwet fractured carbonate reservoirs, however, the capillary driving force for the spontaneous imbibition process is weak and therefore, the waterflooding oil recoveries are low. The recovery efficiency in fractured oil- or mixed-wet carbonate reservoirs can be improved by dissolving low concentrations of surfactants in the injected water to alter the wettability of the reservoir rock to a more water-wet state. This wettability alteration accelerates the spontaneous imbibition of water into matrix blocks, thereby increasing the oil recovery during waterflooding. Several mechanisms have been proposed to explain 
the wettability alteration by surfactants but none have been verified experimentally. Understanding of the mechanisms behind wettability alteration could help to improve the performance of the process and aid in identification of alternative surfactants for use in field applications. Several researchers noted that for a given rock type, the effectiveness of wettability alteration is highly dependent upon the ionic nature of the surfactant involved. In oil-wet chalk cores, Austad et al. ${ }^{3,4}$ observed that cationic surfactants performed better than anionic surfactants in changing the rock wettability to a more waterwet state. They hypothesized that for cationic surfactants, the mechanism responsible for the wettability alteration in oil-wet carbonate rock is formation of ion pairs between the cationic heads of the surfactant molecules and the acidic components of crude oil adsorbed on the surface of carbonate rock. The ionpair formation could strip the adsorbed layer of crude oil components off the rock surface, exposing the originally water-wet carbonate rock. In contrast, anionic surfactants molecules form a monolayer on the surface of carbonate rock through hydrophobic interaction of the tails of the surfactant molecules with the adsorbed crude oil components on the rock surface. The layer of adsorbed surfactants with the hydrophilic head groups covering the originally oil-wet rock surface could change the wetting state of the rock surface toward more water-wet. Since the hydrophobic interactions are much weaker than the ion-pair interactions, this could explain why cationic surfactants performed better than the anionic surfactants in altering the wettability of the carbonate rock to a more water- wet state. However, none of these hypotheses were verified experimentally. In this study, we performed mechanistic studies to test the hypotheses proposed in the literature on the mechanisms of wettability alteration by surfactants. Both synthetic polyethylene cores and Berea cores aged in crude oil were used as porous media. A cationic surfactant (C12TAB) and an anionic surfactant (STEOL CS-330) were used to study the wettability alteration in cores of different wetting states. Adsorption isotherms and Amott-Harvey wettability indices were obtained measured to characterize the wettability alteration process. In addition, we also explored the potential of improving the effectiveness of the wettability alternation process by using a biosurfactant, surfactin, with higher charge density on the head group of the surfactant molecules. 


\section{Materials and Methods}

\section{Materials}

Crude oil from the Lansing Kansas City $\mathrm{C}$ zone reservoir was used for aging the cores. It has a density of $0.82 \mathrm{~g} / \mathrm{cm}^{3}$ and a viscosity of $4.58 \mathrm{cp}$ at $45^{\circ} \mathrm{C}$. It was centrifuged and then filtered through a $2.7 \mu \mathrm{m}$ cellulose filter before use. Soltrol 130 (Chevron Philips Chemical Company) which is a commercial mixture of C10-C10 isoalkanes was used as oil phase in all IFT measurements, imbibition and flow tests. Soltrol 130 density and viscosity at $25^{\circ} \mathrm{C}$ are $0.754 \mathrm{~g} / \mathrm{cm}^{3}$ and $1.42 \mathrm{mPa} \cdot \mathrm{s}$ respectively. Synthetic brine $(10 \mathrm{~g} / \mathrm{l} \mathrm{NaCl})$ was used in all experiments with sandstone cores. Cationic surfactant dodecyltrimethylammonium bromide $(\mathrm{C} 12 \mathrm{TAB}, \mathrm{MW}=308.4)$ was obtained from Sigma as a $99 \%$ pure powder and dissolved in deionized water or brine as required. Anionic surfactant sodium laureth sulfate $($ STEOL CS-330, MW $=404.5)$ provided by Stepan Chemical Company was used as received as an aqueous solution with a purity of $24 \%$, and diluted as required. Surfactin (a biosurfactant produced by growing Bacillus subtilis on high-starch medium such as agricultural waste stream, MW = 1047.0) was characterized and provided by Idaho National Laboratory (INL). Molecular structures of surfactants used are shown in Figure 1. Berea sandstone cores and oil-wet synthetic cores made of polyethylene and obtained from Pore Technology Inc. were used in the study. Berea cores had permeabilities of 490$590 \mathrm{md}$ and porosity of $21 \%$. Synthetic cores had permeabilities of 550-580 md and porosity of 31$33 \%$. Table 1 summarizes the characteristics of all the cores used. 


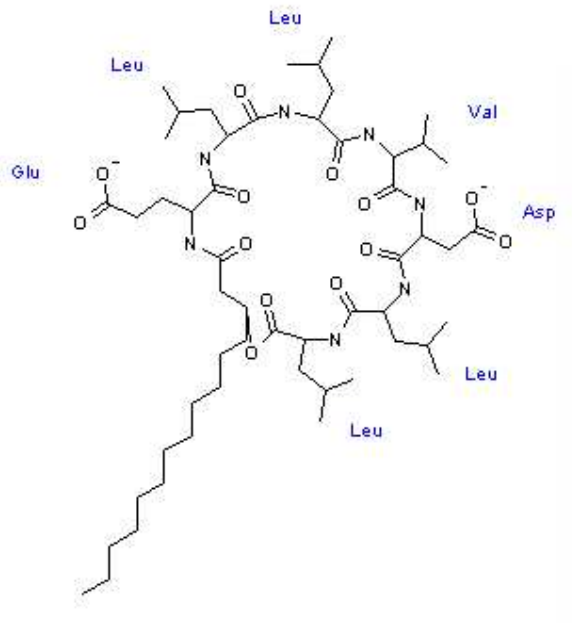

(a)

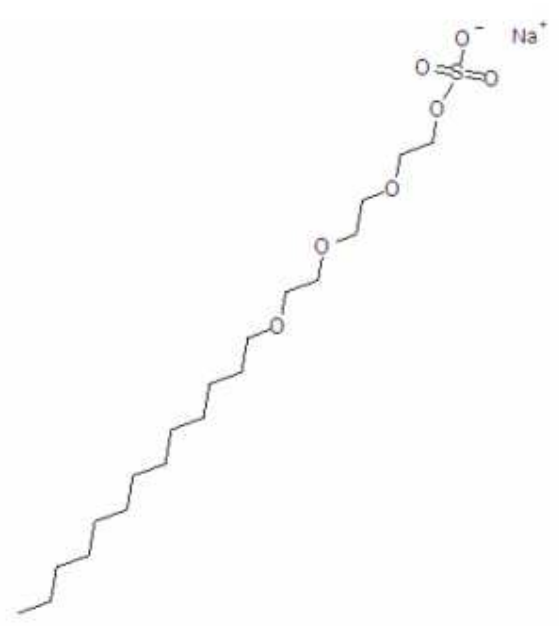

(b)

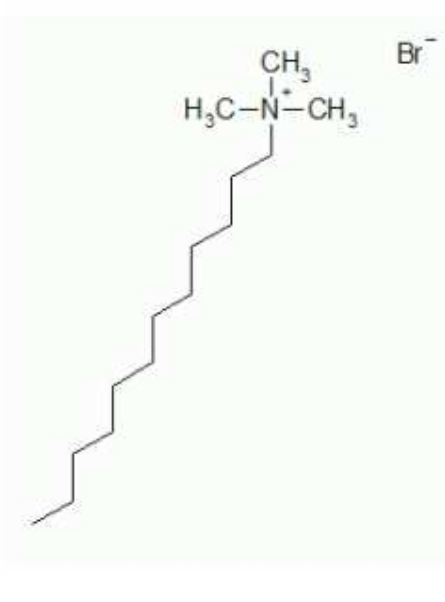

(c)

Figure 1 Molecular structure of surfactants (a) surfactin (b) sodium laureth sulfate, SLS (c) dodecyltrimethylammonium bromide, DTAB

Table 1 Core properties

\begin{tabular}{|l|c|c|c|c|c|c|}
\hline Core & Length (cm) & Diameter (cm) & $\begin{array}{c}\text { Area } \\
\left(\mathrm{cm}^{2}\right)\end{array}$ & PV (ml) & $\phi(\%)$ & k (md) \\
\hline \multicolumn{7}{|c|}{ Berea sandstone cores } \\
\hline B02 & 6.19 & 3.76 & 11.1 & 14.6 & 21 & 490 \\
\hline B03 & 6.35 & 3.76 & 11.1 & 14.9 & 21 & 510 \\
\hline B04 & 7.17 & 3.82 & 11.4 & 17.8 & 21 & 590 \\
\hline B05 & 7.17 & 3.81 & 11.4 & 17.2 & 21 & 560 \\
\hline & 6.62 & 3.73 & 11.0 & 22.4 & 33 & 560 \\
\hline S02 & 6.69 & 3.74 & 11.0 & 21.7 & 31 & 550 \\
\hline S03 & 6.75 & 3.74 & 11.0 & 24.1 & 32 & 580 \\
\hline S04 & \multicolumn{2}{|c|}{ Synthetic cores } & & & \\
\hline
\end{tabular}

\section{Methods and measurements}

Interfacial tension between equal volumes of surfactant solution and Soltrol 130 were measured using a

Fisher Model 20 ring tensiometer. Table 2 shows the IFT values vs. Soltrol 130 for both cationic and 
anionic surfactants used in this study at a concentration of $1.0 \mathrm{mmol} / \mathrm{l}$. A surfactant-ion selective electrode (SUR1502 from pHoenix Electrode Co. Houston, TX) was used to determine the concentration of surfactant solutions by titration with either Hyamine 1622 or sodium dodecyl sulfate (SDS), as appropriate. ${ }^{5}$ Acid and base numbers were obtained following the ASTM D-2896 standard test methods ${ }^{6}$.

Table 2 IFT values for $1.0 \mathrm{mmol} / \mathrm{l}$ surfactants vs. Soltrol 130

\begin{tabular}{|l|c|}
\hline \multicolumn{1}{|c|}{ Surfactant } & $\begin{array}{c}\text { IFT vs. Soltrol 130 } \\
(\mathrm{mN} / \mathrm{m})\end{array}$ \\
\hline STEOL CS-330 & 7 \\
\hline C12TAB & 19 \\
\hline Surfactin & 4 \\
\hline
\end{tabular}

Imbibition tests were performed using Amott cells where core was placed in the cell and immersed in aqueous solution. Oil production was monitored vs. time. For oil imbibition, a modified cell was used to monitor the water production vs. time.

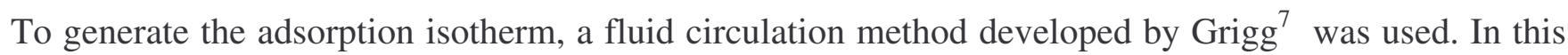
method a surfactant solution was re-circulated through a core for $24 \mathrm{~h}$ and the initial and final concentrations determined by titration against Hyamine 1622 (anionic surfactants, surfactin and STEOL CS-330) or SDS (cationic surfactant, C12TAB) using a surfactant electrode connected to a $\mathrm{pH}$ meter to find the isoelectric point. The adsorption value at each equilibrium concentration was calculated by mass balance.

Synthetic cores were cut into 3-inch lengths. Two synthetic cores were used to generate adsorption isotherms of the two surfactants. Sandstone cores were first characterized using $10 \%$ brine solution and then initial water saturations were established by flooding the cores with Soltrol 130. The Soltrol 130 was displaced with a Lansing Kansas City crude oil and cores were aged in oven at $90{ }^{\circ} \mathrm{C}$ for one month to render them oil-wet. Synthetic cores were preferentially more air-wet than water-wet and lost water 
by gravity drainage as soon as the cores were taken out of the Hassler-Type coreholder. To ameliorate this problem, all the imbibition tests on these cores were performed while the cores were contained in a specially designed coreholder.

\section{Wettability and Fluid/Rock Interactions}

Wettability is defined as "the tendency of one fluid to spread on or adhere to a solid surface in the presence of other immiscible fluid". ${ }^{8}$ The fluid with the higher affinity toward the solid surface is called the wetting phase, the other fluid is the non-wetting phase. Wettability is very important in oil recovery processes and has a strong impact on distribution, location and flow of oil and water in reservoir during production. ${ }^{9-14}$ A rock sample that imbibes only water spontaneously is said to be water-wet, one that imbibes only oil spontaneously is called oil-wet. Mixed wettability is characterized by isolated water and oil-wet areas on the rock surface that are inter-connected. ${ }^{15}$ It is generally considered that oil reservoirs were created by accumulation of hydrocarbons in a rock originally filled with water, and therefore it was assumed that rock surface in all oil reservoirs were originally water-wet. ${ }^{14,}$ 16-18 However, observations from wettability tests on cores from different reservoirs indicated that some reservoir rocks are oil-wet. ${ }^{19}$ It has been recognized by many authors that certain components, mainly the heavy asphaltene and resin fractions of crude oil are able to alter the wettability of the original water-wet rock by adsorption onto the rock surface. ${ }^{8,18,20-28}$ The most important components in the crude oil responsible for the wettability alterations are those carrying a charged group such as an acid or base. ${ }^{9,26,29}$ Carbonate rocks usually carry positive charges on the surface and therefore, have a higher affinity toward the acidic components in crude oil, whereas the negatively charged surface of sandstone rocks has a stronger attraction toward the basic components in crude oil. ${ }^{30}$ Figure 2 is a schematic representation of how this process could change the wettability of an originally water-wet reservoir rock toward a more oil-wet state. 


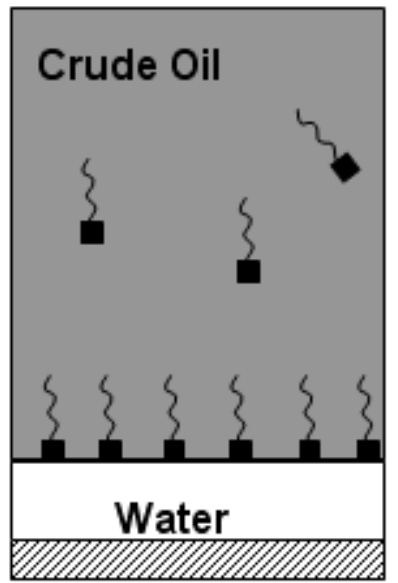

Solid is covered with water initially.

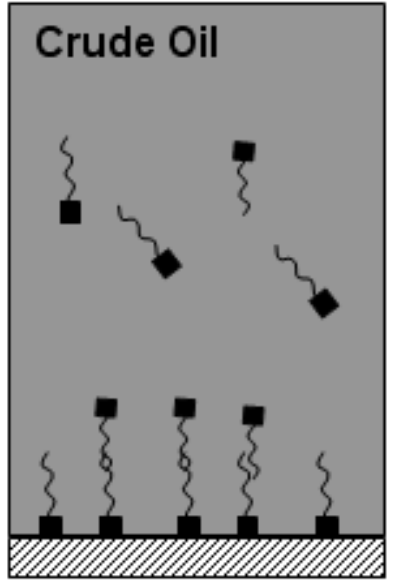

Crude oil components adsorb during aging.

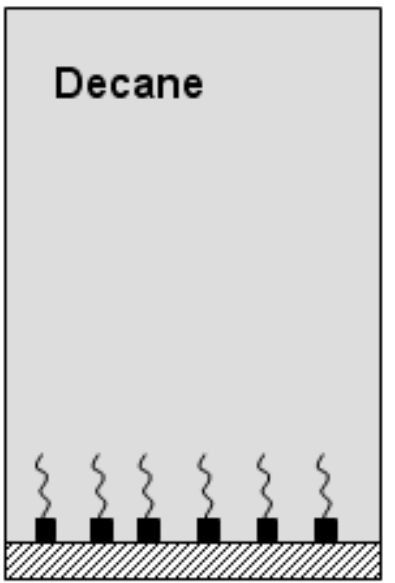

Adsorbed layer is retained after rinse with a lighter oil.

Figure 2 Development of oil-wetness. Squares are organic materials from crude oil

$(\text { After Buckley et al. })^{30}$

Several methods may be used to measure the wettability of a porous medium; the Amott-Harvey $\operatorname{method}^{9}$ was used in this work. This method is an extension of the wettability test introduced by Amott. ${ }^{31}$ This method, after establishing the initial water saturation $\left(S_{\mathrm{iw}}\right)$ consists of the following steps (Figure 3): 


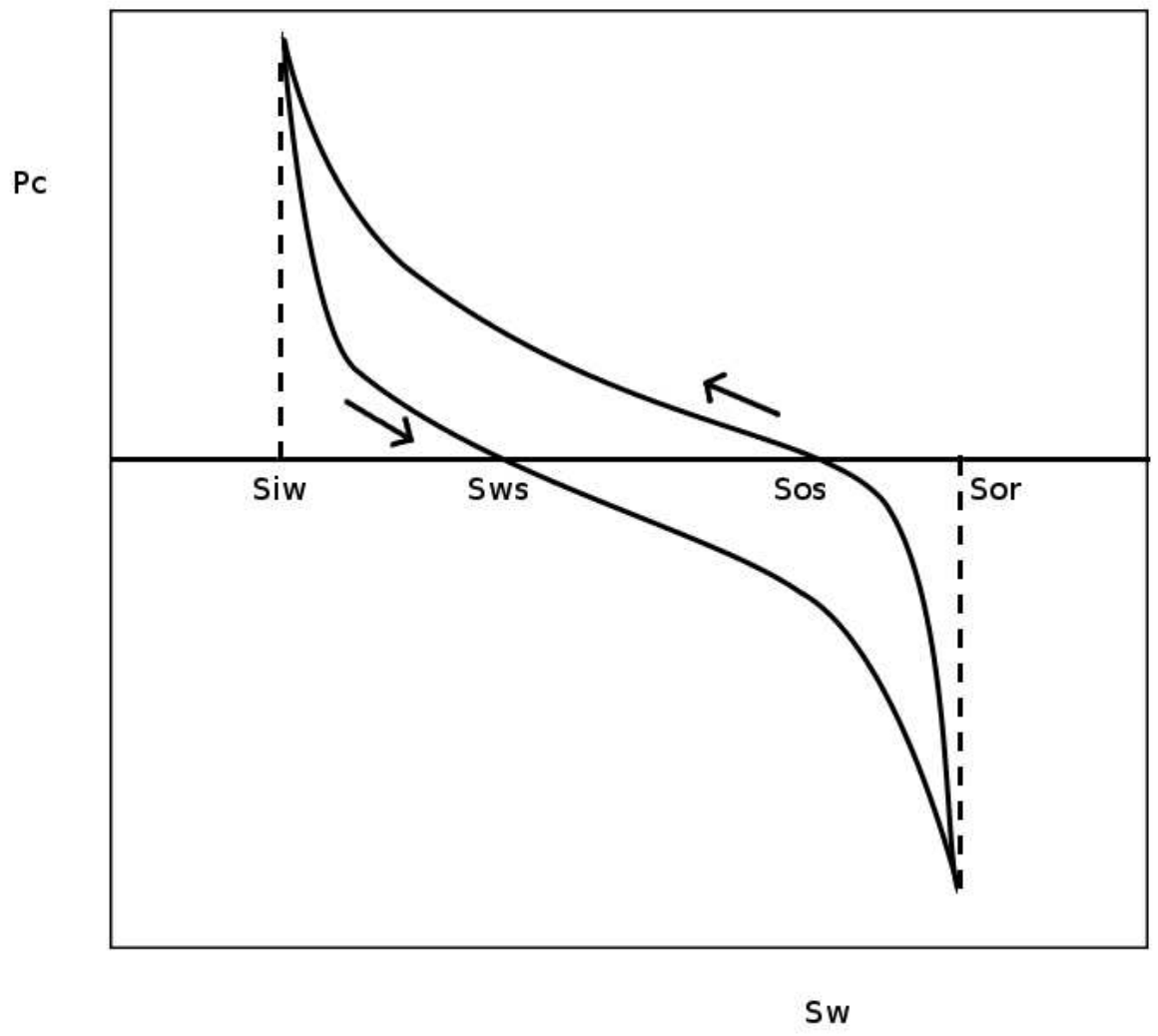

Figure 3 Capillary curve illustrating the steps needed in calculating the $\mathrm{I}_{\mathrm{A}-\mathrm{H}}$ wettability index

1. Spontaneous imbibition of water to reach $S_{w s}$

2. Flooding the core with water (forced imbibition) to reach residual oil saturation $\mathrm{S}_{\text {or }}$

3. Spontaneous imbibition of oil to reach $\mathrm{S}_{\mathrm{os}}$

4. Flooding the core with oil to reach initial water saturation, $S_{\text {iw }}$

The water wettability index, $I_{w}$, The oil wettability index, $I_{0}$, and the relative displacement index (Amott-Harvey) $\mathrm{I}_{\mathrm{A}-\mathrm{H}}$ can then be defined as:

$$
I_{w}=\frac{S_{w s}-S_{i w}}{S_{w f}-S_{i w}}, \quad I_{o}=\frac{S_{o s}-S_{o r}}{S_{o f}-S_{o r}}, \text { and } \quad I_{A-H}=I_{W}-I_{O},
$$

Where

$\mathrm{S}_{\mathrm{iw}}=$ initial water saturation

$\mathrm{S}_{\mathrm{ws}}=$ water saturation after spontaneous imbibition of aqueous phase

$S_{\mathrm{wf}}=$ water saturation after forced imbibition of aqueous phase 
$\mathrm{S}_{\mathrm{or}}=$ residual oil saturation

$\mathrm{S}_{\mathrm{os}}=$ oil saturation after spontaneous imbibition of oil phase

$\mathrm{S}_{\mathrm{of}}=$ oil saturation after forced imbibition of oil phase

$\mathrm{I}_{\mathrm{A}-\mathrm{H}}$ varies between +1 for strongly water-wet system and -1 for strongly oil-wet systems. Cuiec ${ }^{29}$

considers a system as water-wet when $+0.3 \leq I_{A-H} \leq+1$, intermediate for $-0.3 \leq I_{A-H} \leq+0.3$, and oilwet for $-1 \leq I_{A-H} \leq-0.3$.

\section{Results and Discussion}

In this study, we performed mechanistic studies to test the hypotheses proposed in the literature for the mechanisms of wettability alteration by surfactants. Austad et al. , $^{3,4}$ observed that in oil-wet chalk cores, both cationic and anionic surfactants could alter the rock wettability toward a more water-wet state, however, the cationic surfactants were more effective than the anionic surfactants in the wettability alteration process. In their experiments, chalk cores were first aged in a crude oil at $90{ }^{\circ} \mathrm{C}$. During the process, the adsorption of negatively charged carboxylate groups from crude oil on the positively charged chalk surface changed the rock wettability toward oil-wet. They proposed that cationic surfactants could alter the wettability of the oil-wet chalk surface toward a more water-wet state by forming ion pairs between the cationic head groups and the negatively charged carboxylate groups adsorbed on the rock surface. The ion-pair is resulted from the strong electrostatic interactions and was further stabilized by hydrophobic interactions. In the surfactant literature, the product of reaction between carboxylates and organic ammonium compounds is referred to a "cat-anionic surfactant" 32 . The ion-pair formation could strip the adsorbed layer of crude oil components off the rock surface, exposing the originally water-wet carbonate rock. For anionic surfactants, they claimed that the surfactant molecules could form of a monolayer on the rock surface through hydrophobic interactions with the adsorbed crude oil components. The layer of adsorbed surfactants with the hydrophilic head groups covering the originally oil-wet rock surface could then change the wetting state of the rock surface toward more water-wet. Since the hydrophobic interactions are much weaker than the ion-pair interactions, they proposed that this could explain why cationic surfactants performed better than the 
anionic surfactants in altering the wettability of the carbonate rock to a more water-wet state. However, none of the hypotheses for the wettability alteration were verified experimentally. In the following, we discuss results from our experiments designed to test the hypotheses proposed by Austad et al. ${ }^{3,4}$.

\section{Wettability Alteration by Ion-pair Formation}

Standnes and Austad ${ }^{4}$ observed accelerated imbibition rates with the cationic surfactant dodecyltrimethylammonium bromide $(\mathrm{C} 12 \mathrm{TAB})$ present in the aqueous phase for oil-wet chalk cores (made oil-wet by flooding with and aging in crude oil) and related that to the ability of the surfactant to make the chalk surface more water-wet. They proposed that that ion-pair formation between the positive head groups of the cationic surfactant molecules and the negatively charged adsorbed material, mostly carboxylic groups from crude oil on the surface of the chalk, is the mechanism responsible for making the core more water-wet.

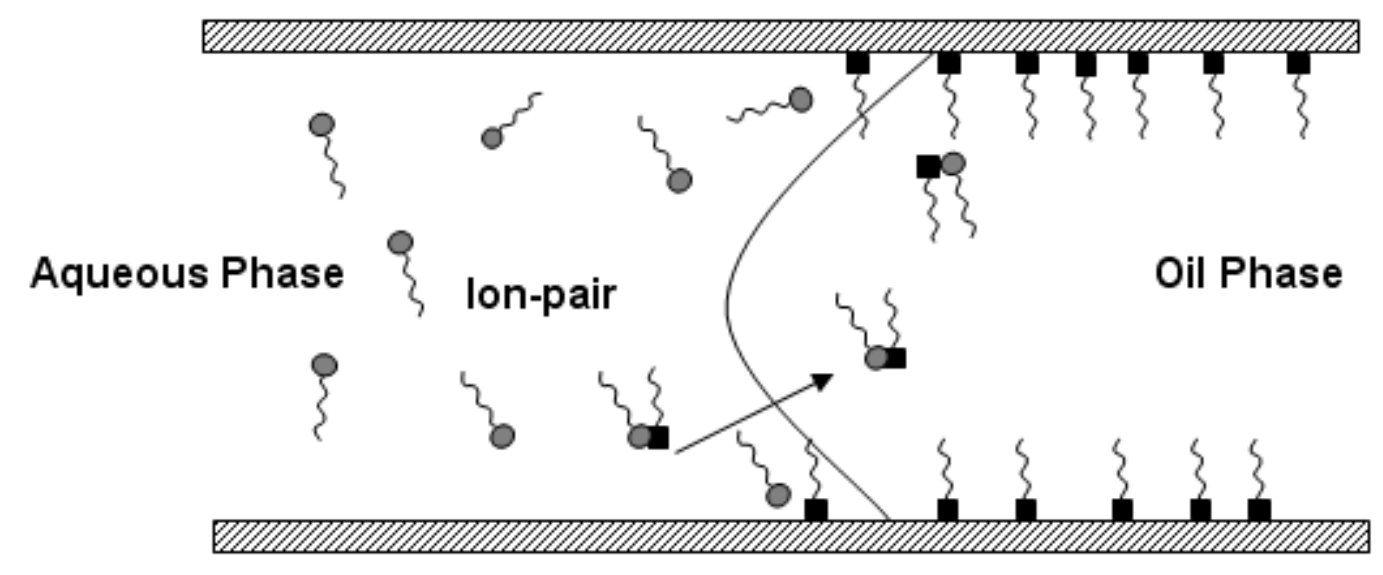

Figure 4 Schematic model of suggested wettability alteration mechanism by cationic surfactant

C12TAB. Circles are cationic surfactant molecules and squares are anionic organic materials from

$$
\text { crude oil (After Standnes) }{ }^{33}
$$

The ion-pair formation is driven by electrostatic interactions between the head groups and also stabilized by hydrophobic interactions between the tail sections. As shown in Figure 4, the formation of ion pairs could strip the adsorbed layer of crude oil components from the rock surface, exposing the originally water-wet rock surface. The ion pairs formed during the process would no longer be water 
soluble and therefore, would move readily across the oil/water interface into the oil phase leaving the free surfactant molecules in the water phase to associate with the adsorbed crude oil components near the oil/water interface (Figure 4). In this way, the surfactants could change the wettability of the rock surface successively to a more water-wet state.

If the proposed mechanism is correct, we should expect anionic surfactants to be more effective in changing the wettability of oil-wet sandstone rock. The wettability of the originally strongly water-wet sandstone rock can be altered toward the oil-wet state by aging it in crude oil at elevated temperatures. Buckley et al..$^{30}$ demonstrated that the negatively charged sandstone surface has a higher affinity toward the positively charged basic components in crude oil and therefore crude oils with larger fraction of basic components are more effective in turning the sandstone rock oil-wet. After the aging process, the surface of the sandstone rock is coated with the positively charged basic components originally dissolved in the crude oil. If ion-pair formation is indeed the mechanism for wettability alteration, anionic surfactants should be more effective than cationic surfactants in changing the wettability of sandstone rock toward a more water-wet state because in this case, the electrostatic interaction driving the ion-pair formation exists only between the anionic head groups of the surfactant molecules and the positively charged basic components of the crude oil adsorbed on the sandstone surface.

To test the hypothesis, we performed imbibition tests in Berea sandstone cores using an anionic surfactant, STEOL CS-330; and a cationic surfactant, C12TAB. The reasons for selecting Berea sandstone as the porous medium were its high permeability, homogeneous properties, and strong water wettability. The properties of the Berea sandstone cores used in this study are summarized in Table 1. Core B02 was first saturated and characterized with Soltrol 130. Soltrol 130 was then displaced by crude oil and the core was aged in crude oil in oven at $90{ }^{\circ} \mathrm{C}$ for one month. Core B03 was saturated and characterized with $1 \%$ brine and then the initial water saturation was established by flooding the core with Soltrol 130. To prepare the cores for the aging process, Soltrol 130 was then displaced by crude oil. After that, the cores were aged in crude oil at a temperature of $90{ }^{\circ} \mathrm{C}$ for one month. After aging, they were flooded with Soltrol 130 to displace the crude oil. The cores were then placed in imbibition 
cells in contact with $1 \%$ brine solution and oil production was monitored. Core B02 started producing oil within a few hours of contact with brine solution. However, there was a few days delay before oil production for B03 core. After two weeks, the brine solutions in contact with B02 and B03 cores were replaced with $1.0 \mathrm{mmol} / 1$ solutions of cationic and anionic surfactants (C12TAB and STEOL CS-330, respectively). The IFT values for these surfactants against Soltrol 130 were obtained using a ring tensiometer (Table 2). STEOL CS-330 had an IFT of $7 \mathrm{mN} / \mathrm{m}$ and that of C12TAB was $19 \mathrm{mN} / \mathrm{m}$. Figure 5 shows the results from these two crude oil-aged sandstone cores. It can be seen that over a period of two weeks imbibition in brine, these cores only produced $2 \%$ of original oil in place (OOIP), indicating an initial strong oil-wet state. The oil produced during this period from both cores came from the top surface of the cores, consistent with an imbibition driven by gravity. After replacing the brine with surfactant solutions, in the case of anionic surfactant STEOL CS-330, the core started producing oil from all faces, showing a change in production mechanism from gravity to capillary driven, despite the lower IFT value for this surfactant against Soltrol 130. The core in contact with cationic surfactant produced very little extra oil. These results were in agreement with those expected if ion-pair formation is responsible for the wettability alteration. To check the reproducibility of the test, the same experiment was repeated using two more crude oil-aged sandstone cores B04 and B05. In this test, both cores were first saturated and characterized by Soltrol 130 and then flooded with crude oil and aged with no initial water saturation for one month at $90^{\circ} \mathrm{C}$. The same results were obtained from these cores. The anionic surfactant performed better compared with cationic surfactant as shown in Figure 6.

One may argue that the better performance for STEOL CS-330 is related to the lower IFT value for this surfactant which in turn enhanced the oil production by gravity forces. Inverse Bond number, which is the ratio of capillary to gravity forces, is used to determine if the imbibition is driven by capillary forces (countercurrent flow) or gravity forces (cocurrent flow):

$$
N_{B}^{-1}=C \frac{\sigma \sqrt{\frac{\phi}{k}}}{\Delta \rho g h}
$$


where $C$ is a constant related to the pore geometry ( $C=0.4$ for cylindrical capillaries), $\sigma$ is the IFT $(\mathrm{mN} / \mathrm{m}), \phi$ is the porosity, $k$ is the permeability $\left(\mathrm{cm}^{2}\right), \Delta \rho$ is the density difference between the two immiscible phases $\left(\mathrm{g} / \mathrm{cm}^{3}\right), \mathrm{g}$ is the gravitational acceleration $\left(\mathrm{cm} / \mathrm{s}^{2}\right)$, and $h$ is the length of the core (cm). It is concluded from the work of Schechter et al. ${ }^{34}$ that if $\mathrm{N}_{\mathrm{B}}{ }^{-1}>5$, capillary forces are driving the imbibition process. For $\mathrm{N}_{\mathrm{B}}^{-1}<<1$, the imbibition is dominated by the gravity forces and the flow will be cocurrent. The imbibition mechanism could be the results of combination of capillary and gravity forces if $\mathrm{N}_{\mathrm{B}}{ }^{-1}$ falls in the intermediate range of $1<\mathrm{N}_{\mathrm{B}}{ }^{-1}<5$. Table 3 lists the calculated inverse Bond numbers for all the imbibition tests in this study. These values show that gravity is not the dominant imbibition mechanism in any of the tests, which was expected for the short cores ( $\mathrm{L} \sim 3$ inch) used in this work.

Table 3 Values of the inverse Bond number for the imbibition tests

\begin{tabular}{|ll|c|}
\hline \multicolumn{2}{|c|}{ Imbibition Test } & $\mathrm{N}_{\mathrm{B}}{ }^{-1}$ \\
\hline B02 + C12TAB & (Fig. 5) & 34 \\
B03 + STEOL CS-330 & (Fig. 5) & 12 \\
B04 + C12TAB & (Fig. 6) & 26 \\
B05 + STEOL CS-330 & (Fig. 6) & 10 \\
B02 + Surfactin & (Fig. 7) & 7 \\
B03 + STEOL CS-330 & (Fig. 7) & 12 \\
\hline
\end{tabular}

On the other hand, these sandstone cores were aged in crude oil and their surface is no longer carries the initial negative charge. It was assumed in this study that based on the work of Buckley $e t a l^{35}$. the basic components of crude oil will adsorb onto the rock surface and the net charge will be positive. So there is no electrostatic attraction between the cationic surfactant and the crude oil-aged sandstone rock surface which could result in low adsorptions values for this surfactant onto oil-wet sandstone rock, which rules out the possibility of lower performance due to higher adsorption for this cationic surfactant. Moreover, this will create an electrostatic interaction between the anionic surfactant and the positively adsorbed 
components from crude oil on the surface of the sandstone rock which drives the formation of ion-pair and consequently wettability alteration. It can be seen from the imbibition profiles that by introducing the anionic surfactant, the oil production increased dramatically over the values obtained by brine imbibition. The IFT value for the brine ( $1 \% \mathrm{NaCl}$ solution) vs. Soltrol 130 is about $37 \mathrm{mN} / \mathrm{m}$. That for $1.0 \mathrm{mmol} / 1$ solution of STEOL CS-330 vs. Soltrol 130 is $7 \mathrm{mN} / \mathrm{m}$. An IFT reduction from 37 to $7 \mathrm{mN} / \mathrm{m}$ is expected to result in a decrease in the oil production from a reduction in the IFT contribution to capillary forces. However, in our case, the increase in oil production possibly resulted from wettability alteration of some of the pore surfaces to a more water-wet state by the anionic surfactant through ionpair formation. If the effect from wettability alteration is grater than that from the IFT reduction, a higher production could result. 


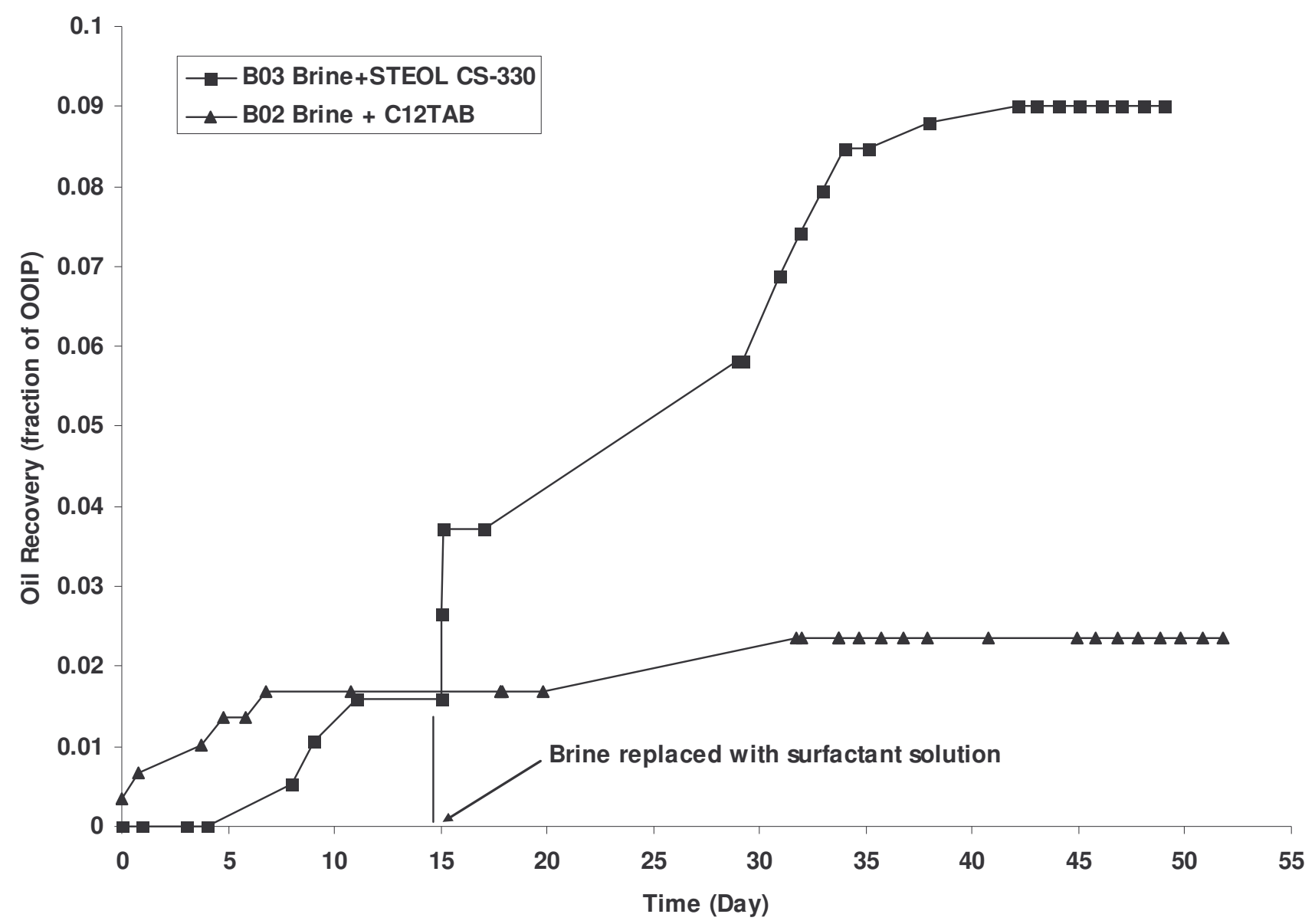

Figure 5 Sandstone cores B02 and B03 imbibition profiles in 1\% brine solution and in $1.0 \mathrm{mmol} / \mathrm{l}$ solutions of cationic and anionic surfactants at room temperature 


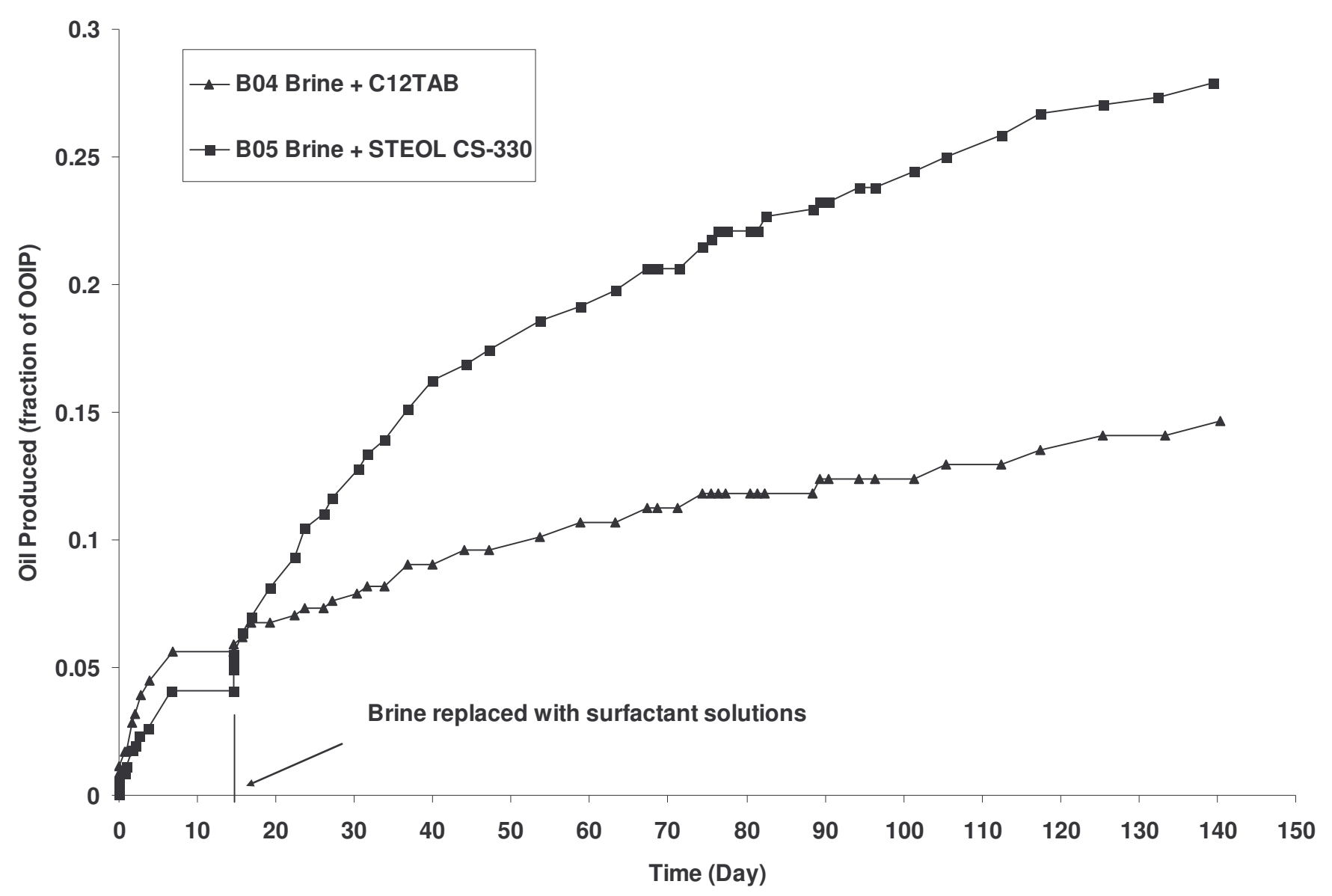

Figure 6 Sandstone cores B04 and B04 imbibition profiles in 1\% brine solution and in $1.0 \mathrm{mmol} / \mathrm{l}$ solutions of cationic and anionic surfactants at room temperature

Based on these findings, we hypothesized that it may be possible to improve the wettability alteration process by increasing the charge density on the head group of the surfactant molecule, since the ion-pair formation is driven by the electrostatic interactions. To test this hypothesis, we used an anionic biosurfactant (surfactin from Bacillus subtilis) with two negative charges on the head group. This surfactant can be produced by growing bacteria on agricultural waste streams and could be cost effective for field applications compared with commercially produced surfactants. Previously used cores B02 and B03 were cleaned by Dean-Stark extraction with toluene after the initial test, dried and were saturated with Soltrol 130, which was displaced with crude oil again and aged in crude oil at $90{ }^{\circ} \mathrm{C}$ for 
one month. They were then flooded with Soltrol 130 and placed in imbibition cells in contact with brine for 10 days. No oil was produced from either of the cores, indicating a more oil-wet state after the second time of aging in crude oil for these cores. The brine solutions were then replaced by $1.0 \mathrm{mmol} / \mathrm{l}$ of anionic surfactants (STEOL CS-330 or surfactin). Figure 7 shows the imbibition profiles for both cores. The IFT values for these surfactants against Soltrol 130 were obtained using a ring tensiometer (Table 2). STEOL CS-330 had an IFT of $7 \mathrm{mN} / \mathrm{m}$ and that of surfactin was $4 \mathrm{mN} / \mathrm{m}$. It is generally believed that spontaneous imbibition rate decreases when capillary forces are reduced by lowering the IFT, due to increased influence of weaker gravity forces. Despite a lower IFT value, it can be seen that surfactin performed well compared with STEL CS-330, and the same discussion regarding the inverse Bond number as above holds. This is consistent with our hypothesis that the performance could be improved by increasing the charge density on the head group of the surfactant molecule. We have been unable to find documentation of this in the literature, however, our data support this hypothesis and we feel it is worthy of further study. These findings suggest that wettability alteration processes might be improved through the use of dimeric surfactants, which have two charged head groups and two hydrophobic tails. Gemini surfactants where the molecules are joined at the head end are likely to be effective when ion-pair formation is the wettability alteration mechanism and Bolaform surfactants, in which molecules are joined by the hydrophobic tails, should be more effective in the case of surfactant monolayer adsorption. This class of surfactants has been studied recently for use in reservoirs with high salinity and temperature. ${ }^{36}$ 


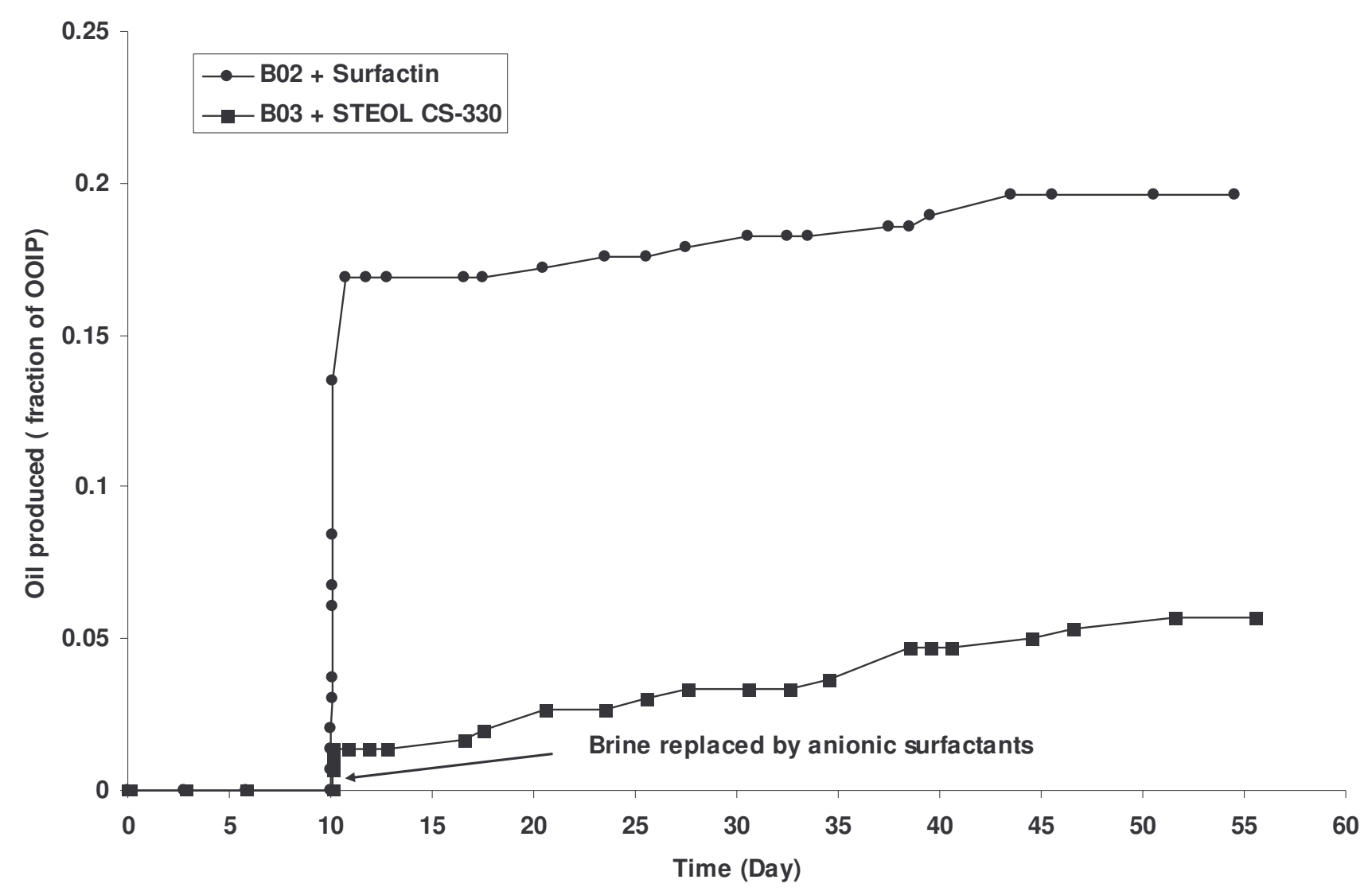

Figure 7 B02 and B03 sandstone cores imbibition profiles in $1 \%$ brine solution and in $1.0 \mathrm{mmol} / \mathrm{l}$ solutions of anionic surfactants

\section{Wettability Alteration by Surfactant Adsorption}

Standnes and Austad ${ }^{4}$ observed that anionic surfactants can also improve the spontaneous imbibition of water into oil-wet chalk cores, albeit not as effectively as cationic surfactants. For the anionic surfactant, the ion-pair formation could not be responsible for the wettability alteration due to the electrostatic repulsion between the anionic head groups and the negatively charged adsorbed crude oil components on the chalk surface. They hypothesized that anionic surfactants could alter the rock wettability by forming a surfactant mono layer on the oil-wet rock surface. They claimed that the surfactant adsorbs via a hydrophobic interaction with the hydrocarbon layer adsorbed on the surface of the chalk as shown in Figure 8, leaving the water soluble head-group of the surfactant pointing toward the solution. This would result in the formation of a thin water zone and create weak capillary forces 
during the imbibition process. This process would occur sequentially at the surfactant/oil/rock interface. Due to the weak hydrophobic interactions, this process should be readily reversible. If this theory is correct, surfactants should be adsorbed only by their hydrophobic tail on a hydrophobic surface, changing the wettability of the surface to a less oil-wet state by having their hydrophilic head-group oriented toward the solution. The adsorption of the surfactant should also be in the form of a monolayer of surfactant molecules and there would be no possibility of forming a bi-layer since the remaining surfactant molecules in solution have the same charge as those adsorbed. To test this hypothesis, completely oil-wet synthetic polyethylene cores were selected to perform imbibition and dynamic adsorption tests. This ensures a complete oil-wet surface and eliminates the possibility of having a mixed-wet state as in the case of a real reservoir core. Also, the polyethylene surface is free of any adsorbed charged components and therefore, the only way for the surfactant molecules to adsorb on the polyethylene surface is through the interaction of their hydrophobic tails with the oil-wet surface. The properties of the synthetic cores used in this study can also be found in Table 1. Results from imbibition tests revealed that, as expected, the polyethylene cores were completely oil-wet with an oil wettability index of 1 . To measure the ability of the surfactants to change the wettability of these cores, these cores were flooded and aged with anionic (STEOL CS-330) and cationic (C12TAB) surfactants at ambient conditions. The procedure was to flood (circulation method) these cores with a known mass and initial concentration of surfactant solution for $24 \mathrm{~h}$ and then age the system for another $24 \mathrm{~h}$. The surfactant solution was then displaced with Soltrol 130 to establish the initial water saturation and then two imbibition cycles were performed on each core.

These tests were repeated to confirm reproducibility of the results. For all cores used and both surfactants, the wettability of the cores changed dramatically. The oil index changed from a value of one to zero in the case of STEOL CS-330 and to a value of 0.3 in the case of C12TAB. The wettability of these cores was changed from a strong oil-wet condition to an intermediate wetting state. Going through the second imbibition cycle, the wettability changed to a more oil-wet state ( $I_{0}$ value close to 1$)$. This suggests that the interactions between the surfactant molecules and the oil-wet surface are very weak, 
which is consistent with the surfactant molecules being attached by their hydrophobic tail to the oil-wet surface of the core and forming a monolayer on the surface.

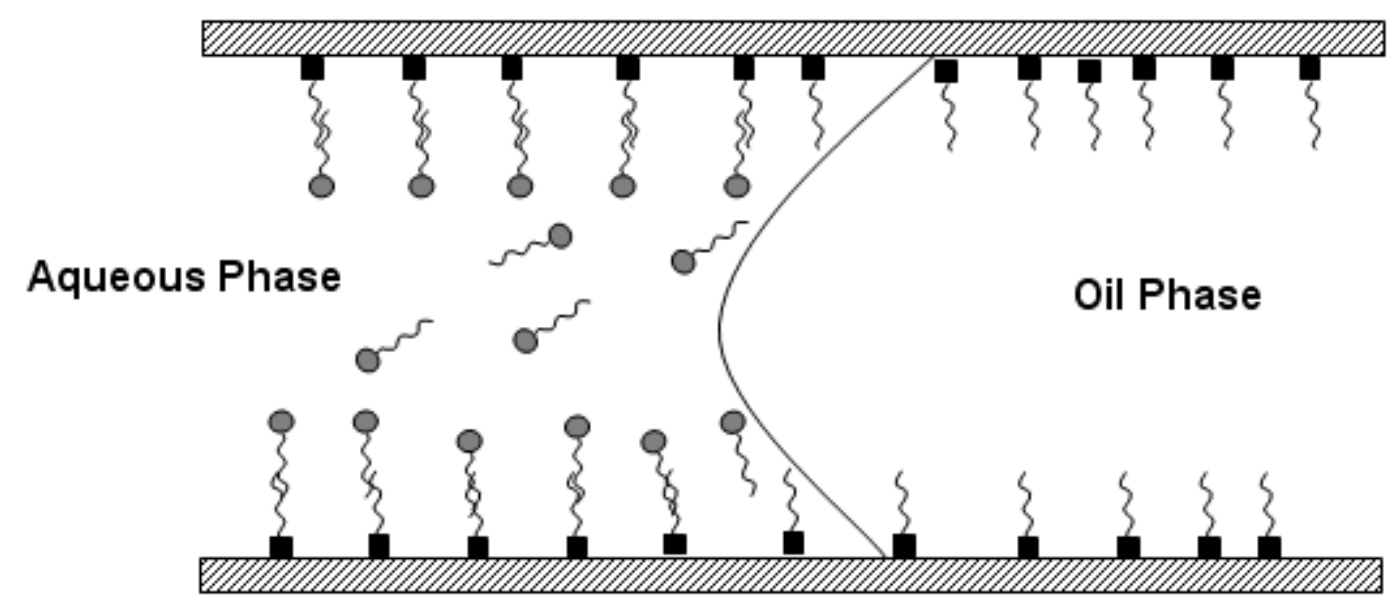

Figure 8 Schematic model of suggested wettability alteration mechanism by anionic surfactant and bilayer formation. Circles are anionic surfactant molecules and squares are anionic organic materials from crude oil (After Standnes) $)^{33}$

Adsorption isotherms obtained for both surfactants on synthetic cores shown in Figure 9 indicated a Langmuir type adsorption for both surfactants which confirms that surfactant molecules formed a monolayer on the oil-wet surface. It can also be seen from this figure that STEOL CS-330 adsorbed more compared with the C12TAB. This may be due to presence of ethoxyl groups in the molecular structure of STEOL CS-330, which may reduce the charge density of the head group, resulting in a better packing and hence a more compact monolayer. The change of wettability back toward the more oil-wet state when going through the second imbibition cycle can be explained by the removal of the adsorbed surfactant layer during the water injection displacing the oil. The hydrophilic head group is oriented toward the solution and increases the chance of removal of surfactant molecules adsorbed on the surface during forced imbibition. In one case (core S04), two aqueous effluent samples from the first and second imbibition cycles were collected and tested for surface tension values. The water has a surface tension of $72.78 \mathrm{mN} / \mathrm{m}$ at room temperature. The effluents 1 and 2 showed surface tension values of 34.5 and $46 \mathrm{mN} / \mathrm{m}$, respectively, indicating the presence of surfactants in effluents with a 
decreasing trend. These findings confirm that an adsorbed monolayer of surfactant molecules can indeed alter the wettability of an oil-wet surface toward a more water-wet state through hydrophobic interaction of the tail sections of the surfactant molecules with an oil-wet surface. Our findings also show that the hydrophobic interactions are weak and this process is reversible. Tables 4-7 summarize the imbibition data for all tests performed. Standnes et $a l .^{37}$ reported the same observation for a nonionic surfactant in oil-wet carbonate cores.

Table 4 Imbibition data for S03 core flooded and aged with STEOL CS-330 at room temperature

\begin{tabular}{|l|c|c|}
\hline Imbibition Cycle & First & Second \\
\hline $\mathrm{S}_{\mathrm{iw}}$ & 0.17 & 0.18 \\
\hline Oil produced by SI of water $(\mathrm{ml})$ & 0.0 & 0.0 \\
\hline $\mathrm{S}_{\mathrm{ws}}$ & 0.17 & 0.18 \\
\hline Oil produced by FI of water $(\mathrm{ml})$ & 12 & 10.7 \\
\hline $\mathrm{S}_{\mathrm{or}}$ & 0.24 & 0.29 \\
\hline $\mathrm{I}_{\mathrm{w}}$ & 0.0 & 0.0 \\
\hline $\mathrm{W}_{\mathrm{iter} \text { produced by SI of oil }(\mathrm{ml})}$ & $<0.1$ & 6.7 \\
\hline $\mathrm{S}_{\mathrm{os}}$ & 0.24 & 0.62 \\
\hline Water produced by FI of oil $(\mathrm{ml})$ & 11.8 & 3.9 \\
\hline $\mathrm{S}_{\text {of }}$ & 0.82 & 0.81 \\
\hline $\mathrm{I}_{\mathrm{O}}$ & 0.0 & 0.63 \\
\hline
\end{tabular}


Table 5 Imbibition data for S02 core flooded and aged with C12TAB at room temperature

\begin{tabular}{|l|c|c|}
\hline Imbibition Cycle & First & Second \\
\hline $\mathrm{S}_{\mathrm{iw}}$ & 0.18 & 0.20 \\
\hline Oil produced by SI of water (ml) & 0.0 & 0.0 \\
\hline $\mathrm{S}_{\mathrm{ws}}$ & 0.18 & 0.20 \\
\hline Oil produced by FI of water (ml) & 11 & 11.2 \\
\hline $\mathrm{S}_{\mathrm{or}}$ & 0.34 & 0.32 \\
\hline $\mathrm{I}_{\mathrm{w}}$ & 0.0 & 0.0 \\
\hline Water produced by SI of oil (ml) & 3.2 & 8.2 \\
\hline $\mathrm{S}_{\mathrm{os}}$ & 0.49 & 0.65 \\
\hline Water produced by FI of oil $(\mathrm{ml})$ & 7.1 & 3.1 \\
\hline $\mathrm{S}_{\text {of }}$ & 0.8 & 0.79 \\
\hline $\mathrm{I}_{\mathrm{o}}$ & 0.33 & 0.73 \\
\hline
\end{tabular}

Table 6 Imbibition data for S04 core flooded and aged with STEOL CS-330 at room temperature

\begin{tabular}{|c|c|c|}
\hline Imbibition Cycle & First & Second \\
\hline $\mathrm{S}_{\mathrm{iw}}$ & 0.12 & 0.13 \\
\hline Oil produced by SI of water $(\mathrm{ml})$ & 0.0 & 0.0 \\
\hline $\mathrm{S}_{\mathrm{ws}}$ & 0.12 & 0.13 \\
\hline Oil produced by FI of water $(\mathrm{ml})$ & 12.8 & 13.0 \\
\hline $\mathrm{S}_{\text {or }}$ & 0.38 & 0.36 \\
\hline $\mathrm{I}_{\mathrm{W}}$ & 0.0 & 0.0 \\
\hline Water produced by SI of oil (ml) & 0.0 & 12.4 \\
\hline $\mathrm{S}_{\mathrm{os}}$ & 0.38 & 0.85 \\
\hline Water produced by FI of oil (ml) & 11.8 & 0.4 \\
\hline $\mathrm{S}_{\mathrm{of}}$ & 0.87 & 0.87 \\
\hline $\mathrm{I}_{\mathrm{o}}$ & 0.0 & 0.96 \\
\hline
\end{tabular}


Table 7 Imbibition data for S02 core flooded and aged with C12TAB at room temperature

\begin{tabular}{|l|c|c|}
\hline Imbibition Cycle & First & Second \\
\hline $\mathrm{S}_{\mathrm{iw}}$ & 0.19 & 0.20 \\
\hline Oil produced by SI of water $(\mathrm{ml})$ & 0.0 & 0.0 \\
\hline $\mathrm{S}_{\mathrm{ws}}$ & 0.19 & 0.20 \\
\hline Oil produced by FI of water $(\mathrm{ml})$ & 11 & 11.2 \\
\hline $\mathrm{S}_{\mathrm{or}}$ & 0.33 & 0.32 \\
\hline $\mathrm{I}_{\mathrm{w}}$ & 0.0 & 0.0 \\
\hline $\mathrm{W}_{\mathrm{iter} \text { produced by SI of oil }(\mathrm{ml})}$ & 3.4 & 8.2 \\
\hline $\mathrm{S}_{\mathrm{os}}$ & 0.51 & 0.65 \\
\hline Water produced by FI of oil $(\mathrm{ml})$ & 7.3 & 3.1 \\
\hline $\mathrm{S}_{\mathrm{of}}$ & 0.80 & 0.79 \\
\hline $\mathrm{I}_{\mathrm{o}}$ & 0.31 & 0.76 \\
\hline
\end{tabular}




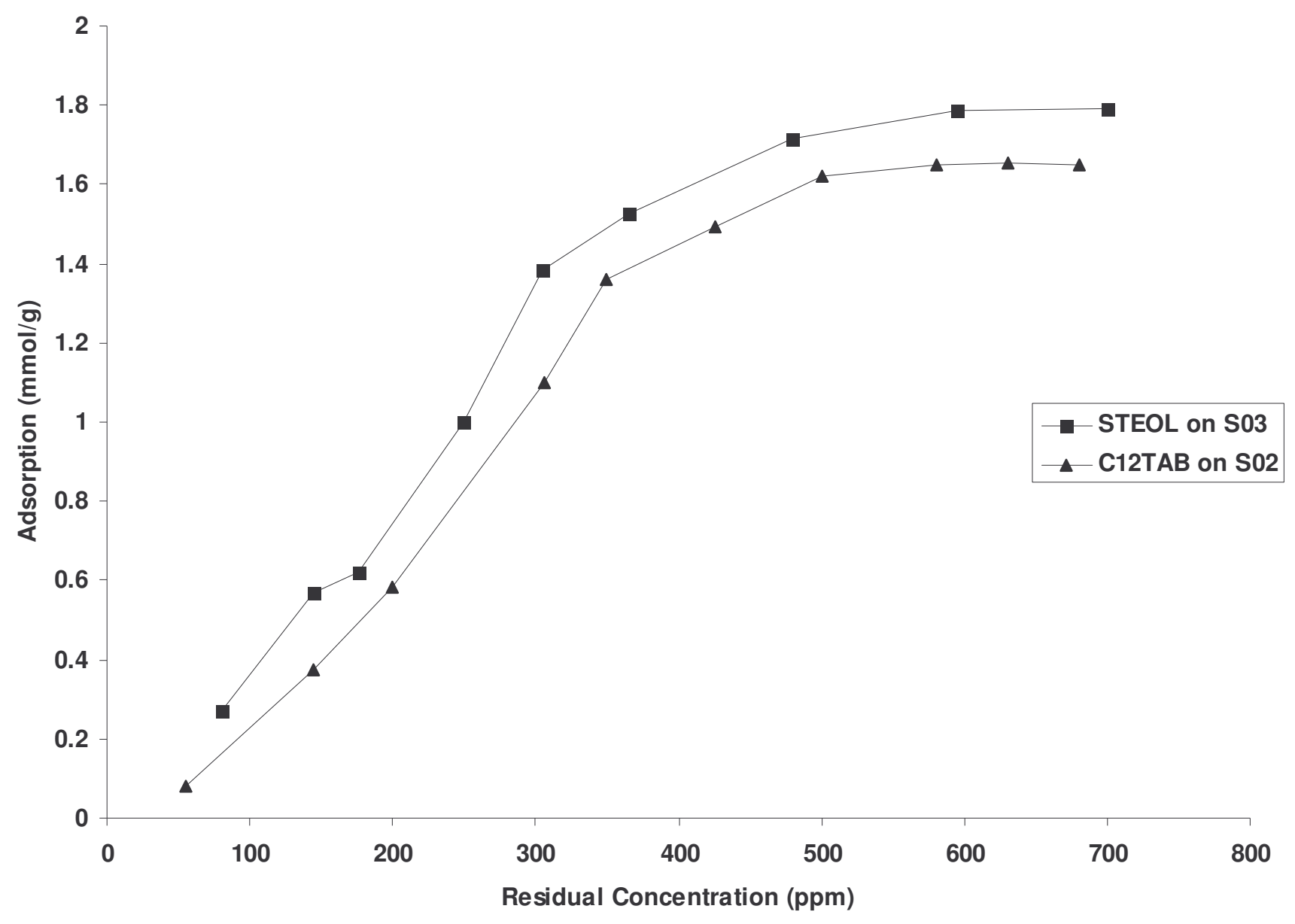

Figure 9 STEOL C-330 and C12TAB adsorption isotherms on synthetic cores at room temperature

\section{Conclusions}

1. Results from this study revealed that ion-pair formation and adsorption of surfactant molecules through interactions with the adsorbed crude oil components on the rock surface are the two main mechanisms responsible for changing the rock wettability toward a more water-wet state.

2. When electrostatic interactions exist between the charged head groups of the surfactant molecules and the adsorbed crude oil components on the rock surface, ion-pair formation is the mechanism responsible for the wettability alteration.

3. In the absence of electrostatic interactions, surfactant adsorption driven by hydrophobic interactions between the tail sections of the surfactant molecules and the adsorbed crude oil components on the rock surface is the main mechanism responsible for the wettability alteration. 
4. Our experimental results confirmed that ion-pair formation between the charged head groups of surfactant molecules and the adsorbed crude oil components on rock surface was more effective in changing the rock wettability toward a more water-wet state than the adsorption of surfactant molecules as a monolayer on the rock surface through hydrophobic interaction with the adsorbed crude oil components.

5. Results from this study demonstrated that surfactants with higher charge density on the head groups were more effective in changing the rock wettability toward a more water-wet state if ion-pair formation is the mechanism responsible for the wettability alteration.

\section{Acknowledgment}

We thank US Department of Energy (DOE) for funding this work through Contract NO. DF-FC26-04NT15523. We extend our thanks to Department of Chemical and Petroleum Engineering and Tertiary Oil Recovery Project (TORP) at the University of Kansas.

\section{References}

1. Allan, J.; Sun, S. Q. In Controls on Recovery Factor in Fractured Reservoirs: Lessons Learned from 100 Fractured Fields Paper SPE 84590 presented at the SPE Annual Technical Conference and Exhibition, Denver, CO, USA, 5-8 October, 2003; Denver, CO, USA, 2003.

2. Roehl, P. O.; Choquette, P. W., Carbonate Petroleum Reservoirs. Springer-Verlag: New York, 1985.

3. Austad, T.; Matre, B.; Milter, J.; Saevareid, A.; Oyno, L., Chemical Flooding of Oil Reservoirs 8. Spontaneous Oil Expulsion from Oil-and Water-wet Low Permeable Chalk Material by Imbibition of Aqueous Surfactant Solutions. Colloids and Surfaces A: Physicochemical and Engineering Aspects 1998, 137, 117-129.

4. Standnes, D. C.; Austad, T., Wettability Alteration in Chalk 2. Mechanism for Wettability Alteration from Oil-wet to Water-wet using Surfactants. Journal of Petroleum Science and Engineering 2000, 28, 123-143.

5. Cross, J., Volumetric analysis of cationic surfactants. In Cationic Surfactants. Analytical and Biological Evaluation, Cross, J.; Singer, E. J., Eds. Marcel Dekker: New York, 1994; pp 140-175.

6. $\quad$ Standard Test Method for Base Number of Petroleum Products by Potentiometric Perchloric Acid Titration West Conshohocken, PA, 2007.

7. Grigg, R. B. Improving $\mathrm{CO}_{2}$ Efficiency for Recovering Oil in Heterogeneous Reservoirs; New Mexico Petroleum Recovery Research Center: Socorro, October 31, 2003; pp Chapter 2 (4-22).

8. Anderson, W. G., Wettability Literature Survey- Part 1: Rock/Oil/Brine Interactions and the Effects of Core Handling on Wettability Journal of Petroleum Technology 1986a, 281, 1125-1144. 
9. Anderson, W. G., Wettability Literature Survey- Part 2: Wettability Measurements. Journal of Petroleum Technology 1986b, 281, 1246-1262.

10. Anderson, W. G., Wettability Literature Survey- Part 4: Effects of Wettability on Capillary Pressure. Journal of Petroleum Technology 1987a, (October), 1283-1300.

11. Anderson, W. G., Wettability Literature Survey- Part 5: The Effect of Wettability on Relative Permeability. Journal of Petroleum Technology 1987b, (November), 1453-1468.

12. Anderson, W. G., Wettability Literature Survey- Part 6: The Effects of Wettability on Waterflooding. Journal of Petroleum Technology 1987c, (December), 1605-1622.

13. Cuiec, L. E., Evaluation of Reservoir Wettability and Its Effect on Oil Recovery. Surfactant Science series. Interfacial Phenomena in Petroleum Recovery 1991, 36 (New York and Basel).

14. Morrow, N. R., Wettability and its Effects on Oil Recovery. Journal of Petroleum Technology 1990, (December), 1476-1484.

15. Salathiel, R. A., Oil Recovery by Surface Film Drainage in Mixed-Wettability Rocks. Journal of Petroleum Technology 1973, (October), 1216-1224.

16. Chernicoff, S., Geology. Second ed.; Houghton Mifflin Company: Boston, 1999.

17. Morrow, N. R., Introduction to Surface Phenomena in Oil Recovery Surfactant Science series. Interfacial Phenomena in Petroleum Recovery 1991, 36, (New York), 1-21.

18. Benner, F. C.; Bartell, F. E., The Effect of Polar Impurities Upon Capillary and Surface Phenomena in Petroleum Production. In Drilling and Production Practices, API: New York, 1942; pp 341-348.

19. Treiber, L. E.; Archer, D. L.; Owens, W. W., A Laboratory Evaluation of the Wettability of Fifty Oil Producing Reservoirs. SPE Journal 1972, 253, (December), 531-540.

20. Bobek, J. E.; Mattax, C. C.; Denekas, M. O., Reservoir Rock Wettability: Its Significance and Evaluation. Petroleum Transactions AIME 1958, 213, 155-160.

21. Marsden, S. S.; Nikias, P. A., The Wettability of the Bradford Sand Producers Monthly 1962, $26,(5), 2-5$.

22. Reisberg, J.; Doscher, T. M., Interfacial Phenomena in Crude Oil-Water Systems. Producers Monthly 1956, (November), 43-50.

23. Denekas, M. O.; Mattax, C. C.; Davies, G. T., Effects of Crude Oil Components on Rock Wettability. Petroleum Transactions AIME 1959, 216, 330-333.

24. Clementz, D. M. In Alteration of Rock Properties by Adsorption of Petroleum Heavy Ends: Implications for Enhanced Oil Recovery, Paper SPE/DOE 10683 presented at the SPE/DOE third joint Symposium on EOR Tulsa, OK, USA, April 4-7, 1982; Tulsa, OK, USA, 1982.

25. Collins, S. H.; Melrose, J. C. In Adsorption of Asphaltene and Water on Reservoir Rock Minerals, Paper SPE 11800 presented at the International Symposium on Oilfield and Geothermal Chemistry Denver, CO, USA, June 1-3, 1983; Denver, CO, USA, 1983.

26. Crocker, M. E.; Marchin, L. M., Wettability and Adsorption Characteristics of Crude-Oil Asphaltene and Polar Fractions. Journal of Petroleum Technology 1988, (April), 470-474.

27. Dubey, S. T.; Waxman, M. H. In Asphaltene Adsorption and Desorption from Mineral Surfaces, Paper SPE 18462 presented at the SPE International Symposium on Oilfield Chemistry Houston, TX, USA, February 8-10, 1989; Houston, TX, USA, 1989.

28. Xie, X.; Morrow, N. R., Contact Angles on Quartz Induced by Adsorption of Heteropolar Hydrocarbons. Journal of Adhesion and Science Technology 2000, 13, (10), 1119-1135.

29. Cuiec, L. In Rock/Crude-Oil Interactions and Wettability: An Attempt to Understand Their Interaction Paper SPE 13211 presented at the SPE 59th Annual Technical Conference and Exhibition Houston, TX, USA, September 16-19, 1984; Houston, TX, USA, 1984.

30. Buckley, J. S.; Liu, Y.; Monsterleet, S., Mechanisms of Wetting Alteration by Crude Oils. SPE Journal 1998, 54-61.

31. Amott, E., Observations relating to the wettability of porous rock. Petroleum Transactions, AIME 1959, 156-162.

32. Karlsson, S.; Backlund, S.; Friman, R., Complexation in the heptanoic acid-heptylamine system. Colloid \& Polymer Science 2000, 278, (1), 8-14. 
33. Standnes, D. C. Enhanced Oil Recovery from Oil-Wet Carbonate Rock by Spontaneous Imbibition of Aqueous Surfactant Solutions. Stavanger College, Stavanger, 2001.

34. Schechter, D. S.; Zhou, D.; Orr, J. F. R., Low IFT Drainage and Imbibition. Journal of Petroleum Science and Engineering 1994, 11, 283-300.

35. Buckley, J. S.; Takamura, K.; Morow, N. R., Influence of Electrical Surface Charges on the Wettung Properties of Crude oils. SPE Reservoir Engineering 1989, 332-340.

36. Barnes, J. R.; Smit, J. P.; Smit, J. R.; Shpakoff, P. G.; Raney, K. H.; Puerto, M. C. In Development of Surfactants for Chemical Flooding at Difficult Reservoir Conditions, Paper SPE 113313 presented at the 16th Symposium on Improved Oil Recovery, Tulsa, Oklahoma, 2008; Tulsa, Oklahoma, 2008.

37. Standnes, D. C.; Nogaret, L. A. D.; Chen, H. L.; Austad, T., An Evaluation of Spontaneous Imbibition of Water into Oil-wet Carbonate Reservoir Cores Using a Nonionic and Cationic Surfactant. Energy \& Fuels 2002, 16, (6), 1557-1564. 